University of Nebraska - Lincoln

DigitalCommons@University of Nebraska - Lincoln

West Central Research and Extension Center, North Platte

Agricultural Research Division of IANR

9-2009

Performance of Solid-State Sensors for Continuous, Real-Time

Measurement of Soil $\mathrm{CO}_{2}$ Concentrations

\author{
Stephen L. Young \\ University of Nebraska - Lincoln, steve.young@usu.edu \\ Francis J. Pierce \\ Washington State University, fran.pierce@gmail.com \\ Jason D. Streubel \\ USDA-ARS, Prosser, WA \\ Harold D. Collins \\ USDA-ARS, Prosser, WA
}

Follow this and additional works at: https://digitalcommons.unl.edu/westcentresext

Part of the Agriculture Commons

Young, Stephen L.; Pierce, Francis J.; Streubel, Jason D.; and Collins, Harold D., "Performance of SolidState Sensors for Continuous, Real-Time Measurement of Soil $\mathrm{CO}_{2}$ Concentrations" (2009). West Central Research and Extension Center, North Platte. 2.

https://digitalcommons.unl.edu/westcentresext/2

This Article is brought to you for free and open access by the Agricultural Research Division of IANR at DigitalCommons@University of Nebraska - Lincoln. It has been accepted for inclusion in West Central Research and Extension Center, North Platte by an authorized administrator of DigitalCommons@University of Nebraska - Lincoln. 


\title{
Performance of Solid-State Sensors for Continuous, Real-Time Measurement of Soil $\mathrm{CO}_{2}$ Concentrations
}

\author{
Stephen L. Young,* Francis J. Pierce, Jason D. Streubel, and Harold P. Collins
}

\begin{abstract}
Recent advances in sensor technology provide a robust capability for continuous measurement of soil gases. The performance of solid-state $\mathrm{CO}_{2}$ sensors (Model GMM220 series, Vaisala, Inc., Helsinki, Finland) was evaluated in laboratory, greenhouse, and irrigated winter wheat (Triticum aestivum L.). In ambient $\mathrm{CO}_{2}$ concentration, the GMM222 sensor averaged $427 \pm 8.3 \mu \mathrm{L} \mathrm{L}-1$. Under variable $\mathrm{CO}_{2}$ concentrations, the sensor was slightly lower than concentrations measured with an infrared gas analyzer (IRGA). In greenhouse pots planted with triticale (Triticale hexaploide Lart.) and an agricultural field of irrigated winter wheat, soil $\mathrm{CO}_{2}$ concentration exceeded the $10,000 \mu \mathrm{L} \mathrm{L} \mathrm{L}^{-1}$ limit of the GMM222. Alternatively, the GMM221 sensor, designed to measure between 0 and $20,000 \mu \mathrm{L} \mathrm{L}^{-1}$, showed soil $\mathrm{CO}_{2}$ concentrations were between 14,000 and $16,000 \mu \mathrm{L} \mathrm{L}^{-1}$. The GMM222 accurately measures real-time soil $\mathrm{CO}_{2}$ concentrations under field conditions that were within the sensor detection limit. However, periods of high biological soil activity require the GMM221 sensor with a higher detection limit.
\end{abstract}

Coll is a MAjOR COMPONENT in the ecosystem carbon $\checkmark$ balance. The primary source of soil $\mathrm{CO}_{2}$ is derived from plants (i.e., rhizosphere respiration) and organisms (i.e., heterotrophic free-living microbes), with a combined contribution to soil carbon stores close to $2 \mathrm{Gt}$ (Tang et al., 2005a; Grace, 2001). Furthermore, belowground soil and plant respiration accounts for the annual processing of one-sixth of the total atmospheric $\mathrm{CO}_{2}$-pool (Paterson et al., 2008).

Various methods have been used to measure soil $\mathrm{CO}_{2}$. The spatial-temporal $\mathrm{CO}_{2}$ flux from soil can be measured with portable (Tang and Baldocchi, 2005) and semipermanent (King and Harrison, 2002) chambers. Soil air samples at different depths and laboratory analyses of soil core samples are two lessautomated methods for determining soil $\mathrm{CO}_{2}$ concentrations (Jassal et al., 2004; Turcu et al., 2005). However, chambers can cause air disturbances, which may alter $\mathrm{CO}_{2}$ concentration in the soil (Tang et al., 2005b), and the long-term continuous measurement with any of these methods is limited by the need for human labor.

The availability of small, solid-state sensors (i.e., GMM220 series) has allowed for the continuous measurement of soil $\mathrm{CO}_{2}$ in field settings, including a Douglas-fir forest [Pseudotsuga menziesii (Mirb.) Franco; Jassal et al., 2004], an oakgrass savanna (Quercus spp.; Tang et al., 2003), a ponderosa

S.L. Young and F.J. Pierce, Washington State Univ., Center for Precision Agricultural Systems, 24106 N. Bunn Rd., Prosser, WA 99350; J.D. Streubel and H.P. Collins, USDA-ARS, 24106 N. Bunn Rd., Prosser, WA 99350. Received 26 May 2009.*Corresponding author(steve_young@wsu.edu).

Published in Agron. J. 101:1417-1420 (2009)

Published online 10 Sept. 2009

doi: 10.2134 /agronj2009.0210N

Copyright (C) 2009 by the American Society of Agronomy, 677 South Segoe Road, Madison, WI 53711. All rights reserved. No part of this periodical may be reproduced or transmitted in any form or by any means, electronic or mechanical, including photocopying, recording, or any information storage and retrieval system, without permission in writing from the publisher. pine forest (Pinus ponderosa P. Lawson \& C. Lawson; Tang et al., 2005b), and a temperate deciduous forest (Hirano et al., 2003). Using only advanced sensor technologies, soil $\mathrm{CO}_{2}$ concentrations measured from periods of 1 mo to 1 yr ranged from 2 to $12 \mu \mathrm{L} \mathrm{L}^{-1}$ in the ponderosa pine forest, 386 to $1,044 \mu \mathrm{L} \mathrm{L}^{-1}$ in the oak-grass savanna, and 6,000 to $10,000 \mu \mathrm{L} \mathrm{L}^{-1}$ in the Douglas-fir forest.

Soil $\mathrm{CO}_{2}$ concentrations in irrigated cropping systems have yet to be quantified using continuous measurement instrumentation such as the GMM222. Seasonal fluctuation in soil $\mathrm{CO}_{2}$ is of importance in these systems, which continually undergo wetting and drying cycles. Irrigation events in semiarid climates of eastern Washington could mimic rain shower events that Tang et al. (2005b) reported increased soil $\mathrm{CO}_{2}$ concentration six-fold from $1000 \mu \mathrm{mol} \mathrm{mol}{ }^{-1}$ to nearly $6000 \mu \mathrm{mol}$ $\mathrm{mol}^{-1}$. Our objectives were to determine the operating parameters and season-long performance of GMM222 sensors in lab and greenhouse testing and field experiments with irrigated winter wheat. While measuring differences in the diurnal patterns of soil $\mathrm{CO}_{2}$ concentrations are important, we were most interested in checking the performance of the GMM220 series sensors under a range of environmental conditions. Therefore, lab, greenhouse, and field data were used to determine accuracy and responsiveness of the sensors with basic statistics (e.g., mean, standard deviation).

\section{METHODS AND MATERIALS}

\section{Site}

All experiments were conducted in lab, greenhouse, and field sites located at the Irrigated Agriculture Research \& Extension Center, Washington State University, Prosser, WA (46 $15^{\prime} 10^{\prime \prime}$ N, 119 44'14" W; $203 \mathrm{~m}$ ). For field testing, the 30-yr (19611990) weather record shows an average annual rainfall at this location of $294 \mathrm{~mm}$, of which, $78 \%$ falls between November and May, and average annual maximum and minimum temperatures of 18.8 and $5.1^{\circ} \mathrm{C}$, respectively, ranging from an

Abbreviations: IRGA, infrared gas analyzer; PVC polyvinyl chloride. 


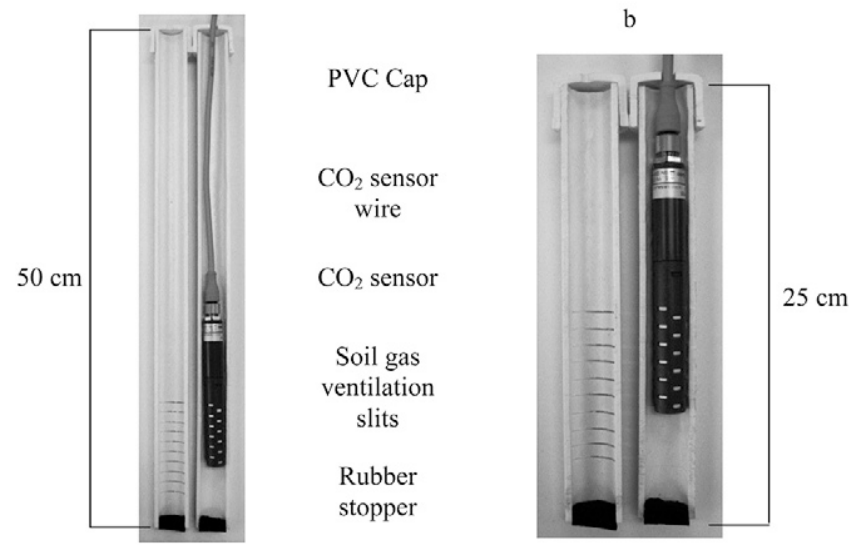

Fig. I. Cut-away view of $\mathrm{CO}_{2}$ sensors inside PVC tubing. The tubing was inserted vertically into the soil, putting the $\mathrm{CO}_{2}$ sensors at (a) $38 \mathrm{~cm}$ and (b) $15 \mathrm{~cm}$ deep.

average maximum of $32.4^{\circ} \mathrm{C}$ in July to an average minimum of $-2.3^{\circ} \mathrm{C}$ in December (WRCC, 2009). The soil is a Warden silt loam (coarse-silty, mixed, superactive, mesic Xeric Haplocambids) (Rasmussen, 1971). Full irrigation is required for crop production.

\section{Soil $\mathrm{CO}_{2}$ Measurement System}

A real-time $\mathrm{CO}_{2}$ measurement system was developed to interface to the GMM220 series $\mathrm{CO}_{2}$ sensors. Each $\mathrm{CO}_{2}$ sensor was connected to a data logger wired to a multidrop bus consisting of a single RS-485 cable. The high power requirements of the $\mathrm{CO}_{2}$ sensors required a single power supply wire connected to a $110-\mathrm{V}$ AC power outlet regulated to $12 \mathrm{~A}$. In the lab, the multidrop bus was connected via RS-485 to a modbus (a serial communications protocol)-to-Ethernet gateway connected directly to the Internet. In the greenhouse and field, the multidrop bus was connected via RS-485 to a wireless modbus bridge consisting of two $900 \mathrm{MHz}$ frequency-hopping spread spectrum radios; one connected on-site to the multidrop bus, and the other connected via a modus-to-Ethernet gateway at a remote location to the Internet. Each sensor was set to record samples every $10 \mathrm{~s}$, and $1 \mathrm{~min}$ averages were automatically transmitted through the RS-485 bus either directly or via the wireless modbus bridge to the modbus-to-Ethernet gateway and automatically stored on a remote database. A Java webbased software application was developed to display real-time data for each pair of sensors in each treatment and to facilitate downloading of raw data for more detailed analysis and interpretation.

\section{Laboratory}

To check for stability over time, a single GMM222 with a range of $0-5000 \mu \mathrm{L} \mathrm{L}^{-1}$ was inserted into a 19-L airtight container and sealed for $2 \mathrm{wk}$. Following the stability test, the accuracy of the GMM222 was measured by comparison with an IRGA (Model ADC-225 MK3, The Analytical Development Company, Hoddeson, UK). The GMM222 was placed in a $420-\mathrm{mL}$ airtight container with known $\mathrm{CO}_{2}$ concentrations beginning at $0,400,800,1200$, and $2000 \mu \mathrm{L} \mathrm{L}^{-1}$. For each concentration, 1-mL samples were manually evacuated using a gastight syringe and immediately analyzed with the IRGA.
Time of sampling was recorded for each manual evacuation to correlate with readings from the GMM222.

\section{Greenhouse}

After lab testing, the GMM222 was subjected to more severe conditions using pots of soil in an environmentally controlled greenhouse. Before installing in soil, a housing unit was fabricated to prevent direct contact of the GMM222 sensor with the soil. Protective units were constructed of $2.5-\mathrm{cm}$ polyvinyl chloride (PVC) tubing and followed a modified design by Tang et al. (2003) and Turcu et al. (2005). Housing units were built for shallow $(15 \mathrm{~cm})$ and deep $(38 \mathrm{~cm})$ insertion of GMM222 sensors into the soil (Fig. 1). Starting $3 \mathrm{~cm}$ from the soil end of the PVC pipe, eleven slits $1 \mathrm{~mm}$ wide and spaced $1 \mathrm{~cm}$ apart were cut halfway through the PVC pipe to allow soil gas to diffuse into the sensors. A rubber stopper was used to plug the open end inserted into the soil. A PVC cap was put over the end extending above the soil surface and protective shrink wrap was applied with a heat gun to secure electric cables that extended to the data logger.

The PVC-housed GMM222 sensors were inserted into 30 -cm-diam. pots filled with soil. Six pots were planted with triticale $\left(115 \mathrm{~kg}\right.$ seed $\left.\mathrm{ha}^{-1}\right)$ and six remained bare soil. A soil probe was used to remove soil just slightly larger than the PVC housing to assure a tight fit by the GMM222 sensors. After installation, continuous measurements were collected for soil $\mathrm{CO}_{2}$ concentration at each sensor for $2 \mathrm{wk}$. The environmental parameters (i.e., temperature, soil moisture) were altered periodically to monitor response of each of the GMM222 sensors. To simulate irrigation, 10 to $1000 \mathrm{~mL}$ of water were applied to each pot using a $60-\mathrm{mL}$ syringe. Diurnal fluctuations in temperature were controlled manually through forced air heat $\left(53^{\circ} \mathrm{C}\right)$ followed by exhaust fans and bags of ice placed on the pots to cool the sensors $\left(25^{\circ} \mathrm{C}\right)$. Similar to lab testing, data was recorded onto a data logger for each GMM222 and later downloaded for analysis and interpretation.

\section{Field}

Following greenhouse testing, eight GMM222 sensors were installed into a field plot of bare soil for $2 \mathrm{wk}$. The sensors were inserted to a depth of $15 \mathrm{~cm}$ and spaced uniformly in a $1-\mathrm{m}^{2}$ grid. Data was recorded with a data logger, similar to lab and greenhouse tests, but transfer of the data was through radio communication, as previously described.

On 22 April, GMM222 sensors were moved from the $1-\mathrm{m}^{2}$ grid and placed in $100 \mathrm{~m}^{2}$ field plots of irrigated winter wheat. Sensors were located close to the center of each plot in the interrows. Shallow and deep sensors were inserted in each plot to depths of 15 and $38 \mathrm{~cm}$, respectively. Power and communication wires connected each sensor to a data logger, which was supplied with power from an alternating current power source that had a 12-A converter. Data acquisition was via radio transmission and Ethernet connection for real-time viewing and downloading.

Field verification of GMM222 sensors was conducted late in the season using soil gas probes. Similar to Jassal et al. (2004), $1 \mathrm{~cm}^{3}$ soil air samples were drawn out of probes buried at the same depths as the GMM222 sensors. The probes were made of thin steel tubing (1.2-cm o.d.) coupled to a fine-mesh screen 


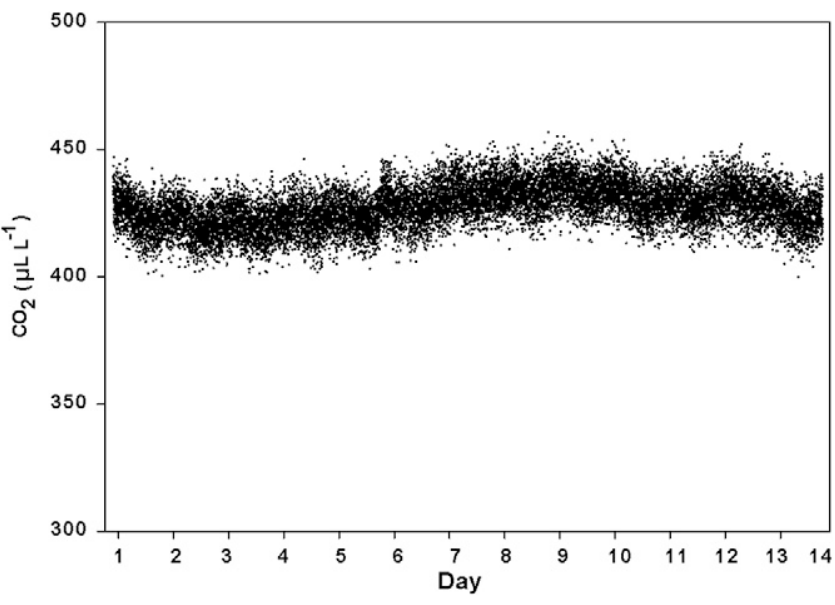

Fig. 2. $\mathrm{CO}_{2}$ measurements recorded every I min over a 2-wk period using a $\mathrm{CO}_{2}$ sensor (Model GMM222, Vaisala, Finland) enclosed in a $19-\mathrm{L}$ airtight container. Average $\mathrm{CO}_{2}$ concentration was $427 \pm 8.3 \mu \mathrm{L} \mathrm{L}^{-1}$.

with a point at the end for insertion into the soil. A silicon rubber septum was placed on the end of the tube located just above the soil surface. Soil air samples were collected using a polyethylene 1-mL medical grade syringe and needle inserted into the septum.

On 15 August, soil gas probes were inserted into irrigated winter wheat plots that contained GMM222 sensors. Two probes were pushed into the soil at a distance of $3 \mathrm{~cm}$ from either side of the sensor. In September and October, soil air samples were extracted from each probe. The samples were taken immediately to the lab and injected into a $\mathrm{CO}_{2}$-free air stream passing through the IRGA. Sample $\mathrm{CO}_{2}$ concentration was determined from the ratio of the area under the concentration versus time curve to that obtained from standard concentrations. The date and time were recorded for comparison with data from GMM222 sensors.

\section{RESULTS AND DISCUSSION}

\section{Lab and Greenhouse}

In the lab tests we conducted, the GMM222 sensor operated according to manufacturer specifications. In the 19-L airtight container, a single GMM222 sensor recorded $\mathrm{CO}_{2}$ concentration slightly higher $\left(400-450 \mu \mathrm{L} \mathrm{L}^{-1}\right)$ than current atmospheric concentrations (see http://cdiac.ornl.gov/, verified 4 Sept. 2009) over a 2 -wk period (Fig. 2). The fluctuations in readings varied by $31 \mu \mathrm{L} \mathrm{L}^{-1}$, which was consistent with calibrations by the manufacturer. In addition, comparisons of the GMM222 sensor to the IRGA revealed an $18 \%$ bias in measuring known concentrations of $\mathrm{CO}_{2}$ (Fig. 3). The nearness of our lab tests to manufacturer specifications was expected under the controlled conditions of the lab.

We were able to simulate soil moisture and temperature extremes that were expected in the field by using controlled conditions of the greenhouse. The GMM222 sensors recorded diurnal patterns in soil $\mathrm{CO}_{2}$ concentration while in close proximity to the soil and the resulting effects from the addition of water and heat. The GMM222 recorded differences in soil $\mathrm{CO}_{2}$ concentrations consistent with other research on soil $\mathrm{CO}_{2}$ concentrations and the effects of diurnal temperature and moisture patterns (see Flechard et al., 2007; Vargas and Allen, 2008). Outlier or extreme measurements by the GMM222 were absent under the imposed conditions, and no external damage to the

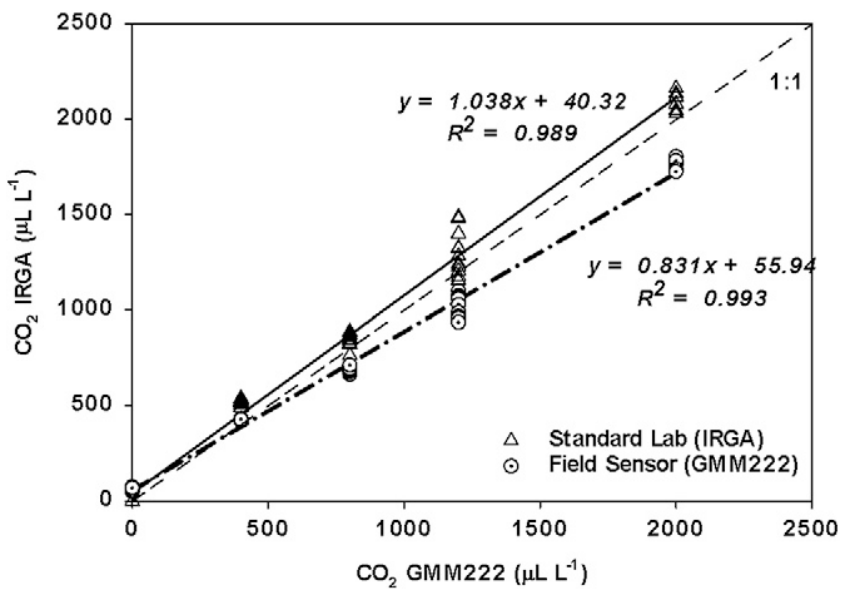

Fig. 3. Measurements from an infrared gas analyzer (IRGA; Model ADC-225 MK3, Analytical Development Company, Hoddeson, UK) and a single $\mathrm{CO}_{2}$ sensor (Model GMM222, Vaisala, Finland) in five known atmospheric concentrations of $\mathrm{CO}_{2}\left(0,400,800,1200\right.$, and $\left.2000 \mu \mathrm{L}^{-1}\right)$. The dashed line is a I:I concentration.

sensor was observed during irrigation events. In the pots of bare soil, $\mathrm{CO}_{2}$ concentration ranged from 700 to $1200 \mu \mathrm{L} \mathrm{L}^{-1}$, which was lower than the pots of triticale. By the end of $2 \mathrm{wk}$, soil $\mathrm{CO}_{2}$ concentrations in triticale were approaching $10,000 \mu \mathrm{L} \mathrm{L}^{-1}$, which is the upper limit of detection for the GMM222 sensors.

Field

The response of GMM220 series sensors for measuring soil $\mathrm{CO}_{2}$ concentration in field conditions was consistent over a 2-wk period (Fig. 4). The variation in soil $\mathrm{CO}_{2}$ concentration between the eight sensors was attributed to changes in soil characteristics (e.g., texture, structure, microbiology) that are known to occur over very narrow spatial scales. The normalized difference between all eight sensors was found to be $\pm 250 \mu \mathrm{L} \mathrm{L}^{-1}$ (data not shown). The successful lab and greenhouse testing supported measured field variability and not failures in sensor performance.

The maximum $\mathrm{CO}_{2}$ concentration of $10,000 \mu \mathrm{L} \mathrm{L}^{-1}$ that could be recorded by the GMM222 was reached on 16 May and remained at this level until late August for the upper sensor and early September for the lower sensor. The

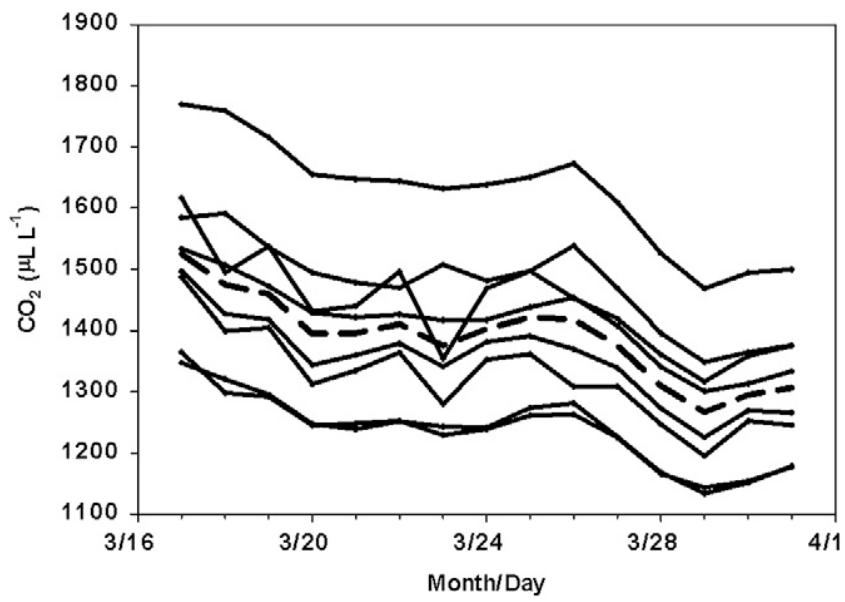

Fig. 4. Comparison of eight $\mathrm{CO}_{2}$ sensors (Model GMM222, Vaisala, Finland) uniformly installed to $15 \mathrm{~cm}$ in a $1-\mathrm{m}^{2}$ grid of bare soil in the field. The dashed line represents average soil $\mathrm{CO}_{2}$ concentration. 


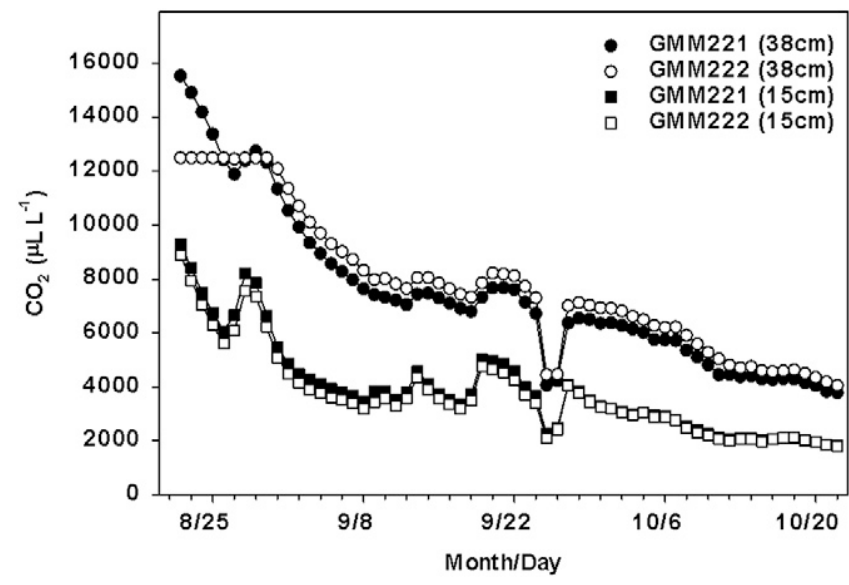

Fig. 5. Late-season soil $\mathrm{CO}_{2}$ concentrations at shallow and deep depths in a harvested winter wheat field. Two different $\mathrm{CO}_{2}$ sensors (Model GMM22I and Model GMM222, Vaisala, Finland) were used to measure shallow $(15 \mathrm{~cm})$ and deep (38 $\mathrm{cm})$ soil $\mathrm{CO}_{2}$ concentrations.

installation of the GMM221 sensor with a range of 0 to $20,000 \mu \mathrm{L} \mathrm{L}^{-1}$ provided values for soil $\mathrm{CO}_{2}$ concentrations $>10,000 \mu \mathrm{L} \mathrm{L}^{-1}$ and matched the GMM222 sensor at concentrations $<10,000 \mu \mathrm{L} \mathrm{L}^{-1}$ (Fig. 5).

While we did not expect to measure soil $\mathrm{CO}_{2}$ levels $>10,000 \mu \mathrm{L} \mathrm{L}^{-1}$, the rates above the threshold for the GMM222 sensor confirmed the high soil $\mathrm{CO}_{2}$ concentration levels recorded in the greenhouse experiment. Our basis for selecting the GMM222 was that a majority of the research by Tang et al. (2003, 2005a, 2005b) and others (Vargas and Allen, 2008) has shown maximum soil $\mathrm{CO}_{2}$ concentrations to be $<1000 \mu \mathrm{L} \mathrm{L}^{-1}$ in semiarid grasslands and forests (but see Jassal et al., 2004; Turcu et al., 2005). The high values in our study could have been due to a design flaw in the sensor PVC housing, thereby allowing soil $\mathrm{CO}_{2}$ to pool and cause a false reading by the GMM222. We checked this by removing the chamber with the sensor from the soil for $18 \mathrm{~h}$ and reinserting back into the same hole. Upon insertion into the soil, the soil $\mathrm{CO}_{2}$ concentration immediately returned to levels from the previous day. Any pooling of $\mathrm{CO}_{2}$ in the chamber would have required more than the few minutes that were observed in this case.

Field soil $\mathrm{CO}_{2}$ concentration measurements from the GMM222 were verified in situ from soil gas samples. On 11 September, soil gas samples from atmosphere probes were $5449 \mu \mathrm{L} \mathrm{L}^{-1}$ and $15,360 \mu \mathrm{L} \mathrm{L}^{-1}$ for shallow and deep depths, respectively. During this same sampling time, $\mathrm{CO}_{2}$ sensors were reading $5798 \mu \mathrm{L} \mathrm{L}^{-1}$ and $12,431 \mu \mathrm{L} \mathrm{L}^{-1}$ at the same depths. A second sampling on 2 October showed probe readings of $8752 \mu \mathrm{L} \mathrm{L}^{-1}$ (shallow) and $13,866 \mu \mathrm{L} \mathrm{L}^{-1}$ (deep), while sensors read $4,753 \mu \mathrm{L} \mathrm{L}^{-1}$ and $12,264 \mu \mathrm{L} \mathrm{L}^{-1}$ for the same depths. Similar trends between probe and sensor were recorded in nearby plots of warm season grasses (data not shown). Soil probe samples taken from the field and analyzed on the IRGA indicated the GMM222 was underestimating soil $\mathrm{CO}_{2}$, similar to the lab tests (see Fig. 3). Future studies that incorporate a season-long soil gas sampling regime for comparison purposes will help to solve the some of the inconsistency between the two methods.

For soil $\mathrm{CO}_{2}$ concentrations $>10,000 \mu \mathrm{L} \mathrm{L}^{-1}$, the GMM221 recorded a maximum of $16,154 \mu \mathrm{L} \mathrm{L}^{-1}$ on 21 August in harvested irrigated winter wheat. The GMM221 sensors were installed in close proximity to the GMM222, and the high soil $\mathrm{CO}_{2}$ value indicates high root and microbial respiration (Jassal et al., 2004).

\section{CONCLUSIONS}

The performance of GMM220 series $\mathrm{CO}_{2}$ sensors was adequate for the range of conditions imposed in lab, greenhouse, and field studies. In addition, the $\mathrm{CO}_{2}$ sensors remained unharmed by wet soil from irrigation and changes in temperature. The GMM222 accurately detected real-time soil $\mathrm{CO}_{2}$ concentrations in irrigated winter wheat. For cropping systems that produce high biomass, a 0 to $10,000 \mu \mathrm{L} \mathrm{L}^{-1}$ detection rate is inadequate for measuring soil $\mathrm{CO}_{2}$ concentration during peak periods of root and microbial activity.

\section{ACKNOWLEDGMENTS}

This research was supported in part by a grant from the USDA CREES National Research Initiative Competitive Grants 2007-3510718279. Project proposal: 2007-03159.

\section{REFERENCES}

Flechard, C.R., A. Neftel, M. Jocher, C. Ammann, J. Leifeld, and J. Fuhrer. 2007. Temporal changes in soil pore space $\mathrm{CO}_{2}$ concentration and storage under permanent grassland. Agric. For. Meteorol. 142:66-84.

Grace, J. 2001. Carbon cycle. p. 609-628. In S.A. Levin et al. (ed.) Encyclopedia of biodiversity. Vol. 1. Academic Press, New York.

Hirano, T., H. Kim, and Y. Tanaka. 2003. Long-term half-hourly measurement of soil $\mathrm{CO}_{2}$ concentration and soil respiration in a temperate deciduous forest. J. Geophys. Res.- Atmospheres 108:4631.

Jassal, R.S., T.A. Black, G.B. Drewitt, M.D. Novak, D. Gaumont-Guay, and Z. Nesic. 2004. A model of the production and transport of $\mathrm{CO}_{2}$ in soil: Predicting soil $\mathrm{CO}_{2}$ concentrations and $\mathrm{CO}_{2}$ efflux from a forest floor. Agric. For. Meteorol. 124:219-236.

King, J.A., and R. Harrison. 2002. Measuring soil respiration in the field: An automated closed chamber system compared with portable IRGA and alkali absorption methods. Commun. Soil Sci. Plant Anal. 33:403-423.

Paterson, E., B. Thornton, A.J. Midwood, S.M. Osborne, A. Sim, and P. Millard. 2008. Atmospheric $\mathrm{CO}_{2}$ enrichment and nutrient additions to planted soil increase mineralization of soil organic matter, but do not alter microbial utilization of plant- and soil C-sources. Soil Biol. Biochem. 40:2434-2440.

Rasmussen, J.J. 1971 Soil survey of Benton County, Washington. Available online at http://websoilsurvey.nrcs.usda.gov/ [accessed 20 May 2009; verified 1 Sept. 2009]. USDA-NRCS, Washington, DC.

Tang, J., and D.D. Baldocchi. 2005. Spatial-temporal variation of soil respiration in an oak-grass savanna ecosystem in California and its partitioning into autotrophic and heterotrophic components. Biogeochemistry 73:183-207.

Tang, J., D.D. Baldocchi, Y. Qi, and L. Xu. 2003. Assessing soil CO $\mathrm{CO}_{2}$ efflux using continuous measurements of $\mathrm{CO}_{2}$ profiles in soils with small solidstate sensors. Agric. For. Meteorol. 118:207-220.

Tang, J., D.D. Baldocchi, and L. Xu. 2005a. Tree photosynthesis modulates soil respiration on a diurnal time scale. Glob. Change Biol. 11:1298-1304.

Tang, J., L. Misson, A. Gershenson, W. Cheng, and A. Goldstein. 2005b. Continuous measurements of soil respiration with and without roots in a ponderosa pine plantation in the Sierra Nevada Mountains. Agric. For. Meteorol. 132:212-227.

Turcu, V.E., S.B. Jones, and D. Or. 2005. Continuous soil carbon dioxide and oxygen measurements and estimation of gradient-based gaseous flux. Vadose Zone J. 4:1161-1169.

Vargas, R., and M.F. Allen. 2008. Environmental controls and the influence of vegetation type, fine roots and rhizomorphs on diel and seasonal variation in soil respiration. New Phytol. 179:460-471.

WRCC. 2009. Prosser, Washington (456763) Western Regional Climate Center http://www.wrcc.dri.edu/ [accessed 20 May 2009; verified 1 Sept. 2009]. WRCC, Reno, NV. 